\title{
Inovação didática no Ensino de Física: um estudo sobre a adoção do método Instrução pelos Colegas (Peer Instruction) no contexto de Mestrados Profissionais em Ensino no Brasil
}

Didactic innovation in Physics Education: a study on the adoption of the Peer Instruction method in the context of Brazilian programs of professional master in teaching

\author{
Ana Amélia Petter ${ }^{*}$, Tobias Espinosa ${ }^{20}$, Ives Solano Araujo10 \\ ${ }^{1}$ Universidade Federal do Rio Grande do Sul, Instituto de Física, Porto Alegre, RS, Brasil. \\ ${ }^{2}$ Universidade Federal do Rio Grande, Instituto de Matemática, Estatísticas e Física, Porto Alegre, RS, Brasil.
}

Recebido em 22 de fevereiro de 2021. Revisado em 29 de abril de 2021. Aceito em 23 de junho de 2021.

Entre outros fatores, a melhoria da qualidade da educação escolar demanda investimentos na formação didáticopedagógica dos docentes. Essa não deve ficar restrita à formação inicial, mas também incluir à continuada, os auxiliando a refletirem sobre suas práticas, construírem e adaptarem soluções inovadoras, à altura dos desafios que encontram em seus respectivos contextos educacionais. Ao encontro desse objetivo, apresentamos os resultados de um estudo sobre a adoção de um dos métodos ativos mais utilizados no ensino de física, o Instrução pelos Colegas (IpC), que vem sendo sistematicamente adotado no contexto dos Mestrados Profissionais em Ensino (MPEs) e no qual se demanda a elaboração e implementação de um produto educacional inovador e disseminável. Elegemos os participantes de nossa investigação a partir de uma busca por dissertações de MPE em que os professores utilizaram o IpC em aulas de Física, no período de 2004 a 2020. Foram selecionadas e analisadas 45 dissertações e um questionário sobre a aplicação do IpC enviado aos seus autores sendo investigadas as modificações mais frequentes no método e algumas das justificativas para essas mudanças. As mudanças mais recorrentes identificadas no estudo dizem respeito às atividades de preparação prévia por parte dos alunos e a dinâmica de aplicação dos testes conceituais em sala de aula. Além disso, levantamos hipóteses explicativas para tais modificações que podem servir de ponto de partida para estudos futuros sobre o tema. Apresentamos também algumas considerações sobre esses resultados no contexto educacional brasileiro, comparando com os resultados de estudos norte-americanos. Palavras-chave: Ensino de Física, Inovação didática, Peer Instruction, Mestrado Profissional em Ensino, Teoria da Difusão de Inovações.

\begin{abstract}
Among other factors, improving the quality of school education requires investments in the didactic-pedagogical training of teachers. This should include pre-service and in-service teacher training, helping them to reflect on their own practices and to build and adapt innovative solutions to face the challenges encountered in their educational contexts. In line with this, this article presents the results of a study on the adoption of one of the most used active methods in the teaching of physics: The Peer Instruction (PI). It is widely adopted in the context of Brazilian Professional Master of Teaching programs (PMTs) in which the development and implementation of an innovative and diffusible educational product is demanded. We chose the participants of our investigation based on a search for dissertations of PMT in which the teachers used the PI in physics classes, in the period from 2004 to 2020. Were selected and analyzed 45 master's degree dissertations and applied a questionnaire about PI to its authors, to investigate the most frequent changes in the method and why these changes were made. The most recurrent changes are related to the preparation assignments and the application of ConcepTests in classroom. In addition, some explanatory hypotheses about it were elaborated and may serve as a starting point for future studies on the topic. Likewise, we compare the results achieved in the Brazilian educational context with the results of North American studies.
\end{abstract}

Keywords: Physics education, Didactic innovation, Peer Instruction, Professional Master of Teaching, Diffusion of Innovation Theory.

\section{Introdução}

A Lei de Diretrizes e Bases da Educação Nacional (LDB 9.394/96) [1] instaura que a educação, dever da família e

\footnotetext{
* Endereço de correspondência:
}

do Estado, tem por finalidade o pleno desenvolvimento do educando, por isso, um dos onze princípios estabelecidos na lei é a garantia da qualidade do ensino. Araujo e Vianna 2] destacam que é consenso na sociedade, e ratificado pela pesquisa em ensino, que a qualidade da educação não pode ser desvinculada da qualidade da 
formação docente, entre outros fatores. Essa formação docente não deve se restringir à formação inicial, e precisa auxiliar os professores a refletirem sobre sua prática e solucionarem problemas em sala de aula por meio da implementação e (re)construção de inovações didáticas.

Dentre as inovações didáticas diretamente relacionadas à ação docente se encontram os métodos ativos de ensino, entendidos como aqueles em que o engajamento dos alunos é promovido atribuindo a eles um papel ativo no processo de aprendizagem e os tornando corresponsáveis pela sua própria aprendizagem [3]. Dentre esses métodos, o Instrução pelos Colegas (IpC) [4, 5], desenvolvido pelo Prof. Eric Mazur da Universidade de Harvard (EUA), é reconhecido internacionalmente e é um dos métodos ativos mais implementados no Ensino de Física 6. No IpC, os alunos são estimulados, durante as aulas, a discutirem com seus colegas suas respostas a questões conceituais, propostas pelo professor. O método visa tornar o aluno mais ativo em sala de aula e engajado no seu processo de aprendizagem [6], e tem como parte de sua base pedagógica a ideia de que um aluno pode aprender com o outro $[5]$.

Em contexto de ensino norte-americano, Henderson e Dancy [7] constataram que o IpC, além de ser o método mais adotado, é também o que sofre mais modificações na implementação, algumas delas eliminando as potencialidades do método. Indícios de que professores que implementam o IpC modificam aspectos essenciais do método também podem ser encontrados no contexto brasileiro [8, 9. Ou seja, tais estudos indicam que o IpC é adotado, mas que é improvável que os professores o adotem da maneira como foi desenvolvido, nos diferentes contextos. Todo método de ensino, de forma explícita ou implícita, assume pressupostos pedagógicos que na maior parte das vezes, com maior ou menor rigor, estão ligados às justificativas para sua adoção [3]. Ao modificar o método para viabilizá-lo em certo contexto educacional, ou aplicá-lo sem considerar adequadamente tal contexto, o docente pode se aproximar ou se afastar das razões pedagógicas que sustentam as estratégias práticas do método. Isto é, as modificações realizadas podem ser simplificações que desvirtuam as intenções originais ou podem potencializá-las, expandindo o método a um novo contexto, particular e inédito [3, [10].

Um dos contextos em que o IpC vem sendo adotado é o dos Mestrados Profissionais em Ensino (MPEs) de Física ${ }^{1}$ O foco dos MPEs está na formação docente, na pesquisa aplicada e no desenvolvimento de produtos e processos educacionais que sejam implementados em condições reais de ensino [1]. Nesses cursos é esperado

\footnotetext{
1 Essa afirmação é baseada na análise dos títulos e resumos de todos os trabalhos do Mestrado Nacional Profissional em Ensino de Física (MNPEF) disponíveis na plataforma Sucupira (disponível em: https://sucupira.capes.gov.br), voltada para a coleta de dados dos programas de pós-graduação nacionais, até o início da pesquisa, isto é, para os anos de 2015 a 2019.
}

que o mestrando desenvolva: um Produto Educacional (PE) inovador e disseminável, que seja analisado e utilizado por outros professores em contextos diversos; e uma dissertação com a descrição dos processos que culminaram no produto e da sua aplicação em situações de ensino [12, 13. Contudo, alguns estudos evidenciam que os PEs não têm sido disseminados a contento, e nem mesmo os autores dos trabalhos continuam aplicando seus produtos após o término do MPE [1416. 2. Apesar dessa constatação, as pesquisas não se ocupam em analisar qualitativamente os produtos e as implementações [17, o que se constitui em uma lacuna para se pensar possíveis soluções para enfrentar a baixa disseminação dos produtos educacionais ${ }^{3}$

Assim, procurando entender os desafios enfrentados pelos docentes ao tentar inovar em sala de aula, no presente estudo buscamos investigar a adoção de um método ativo de ensino pelos professores, ex-alunos do MPE, que o implementaram em suas dissertações e PEs, com base na Teoria da Difusão de Inovações, de Everett Rogers 18 (vide Seção 3). Mais especificamente, analisamos como o Instrução pelos Colegas foi implementado por discentes de cursos de Mestrado Profissional em Ensino do Brasil com temas de Física para o desenvolvimento de suas dissertações, com o intuito de identificar quais as modificações realizadas e as justificativas para essas mudanças.

Com isso, ao longo deste estudo, buscamos responder as seguintes questões de pesquisa: Quais as características do método de ensino Instrução pelos Colegas passam por reinvenções, no sentido atribuído por Everett Rogers, mais frequentemente no contexto de ensino brasileiro dos Mestrados Profissionais em Ensino com temas de Física? Em que medida elas descaracterizam o método? E quais as razões apontadas para essas reinvenções? Além dessas questões, este estudo também tem como objetivo levantar hipóteses sobre os resultados encontrados como ponto de partida para pesquisas futuras.

Para responder essa questão, inicialmente realizamos uma análise de conteúdo, segundo as orientações metodológicas de Bardin [19] (vide Seção 4) nos textos das dissertações e PEs dos professores que implementaram o IpC em aulas de Física durante o MPE. No entanto, devido à falta de informações sobre as características do IpC em alguns desses documentos, foi necessário elaborar e aplicar um questionário, para coleta de dados adicionais sobre a implementação do método com seus autores. Adicionalmente, incluímos questões

\footnotetext{
$\overline{2}$ No nosso estudo, quatorze dos 31 professores (respondentes do questionário) continuaram utilizando o IpC após a conclusão do curso. Dentre os respondentes, outros sete utilizaram o método por até dois anos após o término do curso.

3 Em relação à disseminação de inovações, em uma perspectiva rogeriana 18, a disseminação de um produto educacional implica em sua ampla adoção em diferentes contextos de ensino. A disponibilidade e facilidade de acesso aos produtos é condição necessária, facilitadora da disseminação, mas não suficiente.
} 
relacionadas à implementação do método e de seu PE associado após a conclusão do curso.

Para compreender e analisar o processo de mudança da prática dos professores, bem como elaborar as questões que compõem o questionário, adotamos a Teoria da Difusão de Inovações de Everett Rogers [18, uma das principais referências em estudos sobre adoção e difusão de inovações educacionais [9, 20]. Conforme indicamos na seção 3 a TDI propõe um modelo para tomada de decisões sobre inovações, e procura descrever elementos relevantes para que sejam adotadas e difundidas. Trata-se de uma teoria que aborda inovações de uma forma mais geral, não se restringindo, ou mesmo enfatizando, inovações didáticas. Relações específicas como as que ocorrem entre professores, alunos e materiais didáticos para os diversos contextos educacionais não são explicitamente conceitualizadas, mas podem ser contempladas em conceitos internos à teoria tais como os de "normas sociais", "práticas prévias" e "necessidades percebidas". Para o presente estudo, por uma questão de escopo, não nos aprofundamos em tais leituras.

O estudo descrito no presente artigo está vinculado a uma dissertação de mestrado acadêmico em ensino de Física, cujo projeto foi registrado na Plataforma Brasil sob o número 34076820.3.0000.5347 e teve aprovação do Comitê de Ética em Pesquisa da Universidade Federal do Rio Grande do Sul (UFRGS).

$\mathrm{Na}$ próxima seção apresentamos o método de ensino, Instrução pelos Colegas, e alguns estudos anteriores sobre sua adoção. Ela é seguida pelo referencial teórico (Seção 3), pela metodologia de pesquisa (Seção 4) e pelos resultados e discussões (Seção 5). Por fim, apresentamos, na Seção 6] as considerações finais deste estudo.

\section{O Instrução pelos Colegas e a Adoção de Métodos Ativos de Ensino}

O Peer Instruction, ou Instrução pelos Colegas, é um método ativo de ensino desenvolvido pelo Prof. Eric Mazur da Universidade de Harvard na década de 90 do século XX. Para Araujo e Mazur [21] o principal objetivo desse método é promover a aprendizagem de conceitos fundamentais dos conteúdos em estudo, através da interação entre os estudantes.

O método, como descrito por Mazur [4], inicia-se com a realização de uma tarefa de preparação prévia, anteriormente a aula, por parte do estudante. Nela, o aluno realiza, por exemplo, a leitura de uma parte do livro didático ou assiste a um vídeo, de forma a ser introduzido ao conteúdo. Na primeira versão do método, ao chegar em sala de aula, indicava-se que o professor propusesse questionários aos alunos e, na sequência, utilizasse as respostas deles como base para uma exposição oral sobre os conceitos estudados. Desta maneira, o professor leva em consideração aquilo que o aprendiz já sabe e adapta suas exposições às necessidades apresentadas nas respostas aos questionários.
Em versão atualizada do método, Mazur, em colaboração com Watkins [22] e posteriormente Araujo [21], propõem a combinação do Peer Instruction com o Just-in-Time Teaching ${ }^{4}$ Nessa proposta é recomendado que o professor indique aos estudantes uma Tarefa de Leitura (TL), composta por um material de apoio (texto, vídeo, simulação, ...), uma questão de retorno sobre o entendimento em relação ao conteúdo exposto no material e questões conceituais sobre os conceitos abordados. Ainda antes da aula é esperado que o professor analise as respostas dos alunos e planeje suas exposições para esclarecer as dificuldades dos estudantes, aprofundar a compreensão e apresentar exemplos adicionais, pensando um ensino na medida das necessidades discentes. Assim, o docente destina o tempo em sala de aula para o engajamento ativo dos alunos e não somente para exposição do conteúdo.

Ambas propostas recomendam que o professor, em sala de aula, realize curtas exposições sobre os pontoschave da leitura extraclasse, intercaladas com a apresentação de Testes Conceituais (TCs). Esses TCs são compostos por questões conceituais de múltipla escolha relacionadas aos assuntos discutidos nas exposições orais e objetivam, expor as dificuldades comuns dos alunos na compreensão de cada conceito, relacionado ao conteúdo introduzido na TL. No IpC, o uso de questões conceituais é indicado porque entende-se que a compreensão conceitual é fundamental para aprendizagem de Física.

Após apresentar e interpretar o teste conceitual solicita-se aos estudantes que individualmente escolham uma alternativa e pensem em uma justificativa com base nos argumentos desenvolvidos na aula (cerca de 2 minutos). Para que os alunos se comprometam com a resposta escolhida e se tornem responsáveis pela sua própria aprendizagem, na sequência é realizada uma votação individual. Essa votação pode ser realizada a partir de diferentes sistemas de respostas, como os Flashcards (cartões de resposta), os Clickers ${ }^{\circledR}$ aplicativos para dispositivos com acesso à internet ou ainda com os Plickers ${ }^{\circledR} 6$

Conforme a distribuição das respostas, o professor pode prosseguir a aula de diferentes maneiras. Quando a frequência de acertos for maior que $70 \%$ é aconselhado que o docente explique a questão e prossiga apresentando outra questão do mesmo assunto ou reiniciando o processo para um novo conceito, isto é, realizando uma nova breve exposição dialogada e apresentando uma questão conceitual de um novo ponto-chave. Para uma

\footnotetext{
4 O Just-in-Time Teaching ou Ensino sob medida é um método de ensino proposto em 1996 por Gregory M. Novak que recomenda o uso de tarefas de leitura previamente à aula para tornar o aluno corresponsável pela sua aprendizagem (G. M. Novak, Justin-Time Teaching: Blending Active Learning with Web Technology (Prentice Hall, Upper Saddle River, NJ, 1999) v.1).

5 Controles eletrônicos individuais para os alunos que se comunicam por rádio frequência com um receptor ligado ao computador do professor.

6 Cartões com códigos, detectáveis por smartphones. Disponível em: https://get.plickers.com/
} 
frequência de acertos menor que $30 \%$ é sugerida uma revisão dos conceitos apresentados a fim de esclarecer possíveis dúvidas dos estudantes, seguida de uma nova questão.

É desejável, para o bom desenvolvimento do método, que a frequência de acertos fique entre $30 \%$ e $70 \%$. Nesse cenário, é recomendado organizar os alunos em pequenos grupos (dois a quatro alunos), preferencialmente que tenham escolhido respostas diferentes, e pedir que eles tentem convencer uns aos outros de porque sua resposta é a correta (durante cerca de três minutos). Após a discussão, outra votação individual é realizada e o professor explica a solução para a questão à turma. O professor pode optar por prosseguir a aula realizando outros testes conceituais do mesmo tópico ou reiniciando o processo com uma breve exposição dialogada a respeito de um novo ponto-chave. Tais recomendações visam promover a compreensão conceitual a partir da argumentação, bem como possibilitar que um aluno aprenda com o outro.

Em revisão da literatura sobre a implementação do IpC, Müller, Araujo, Veit e Schell 6 evidenciaram que a maioria das pesquisas são conduzidas em universidades norte-americanas, com destaque às disciplinas de Física. Os impactos da adoção do método, conforme relatados na literatura, foram positivos tanto na aprendizagem conceitual dos estudantes, como na habilidade de resolução de problemas e no desempenho acadêmico.

Além disso, a maioria dos estudos apontam que os estudantes desenvolvem sentimentos positivos com relação ao método e a sua aprendizagem dos conteúdos. Em relação à implementação do IpC investigada nessa revisão, foram constatadas modificações realizadas pelos professores, como a integração do método com outras metodologias e mudanças nas etapas do IpC. Segundo os autores, as modificações, apesar de demonstrarem a flexibilidade do método, também apontam a necessidade de uma investigação dos impactos dessas modificações nos contextos em que são implementadas.

Nesse sentido, Dancy, Henderson e Turpen [8] realizaram entrevistas com 35 professores universitários de Física para analisar como eles tomaram conhecimento e implementaram o método de ensino IpC. Para isso, os autores se fundamentaram na Teoria da Difusão de Inovações (TDI) [18, mesmo referencial que adotamos em nossa pesquisa. Após a definição de nove elemento: ${ }^{7}$

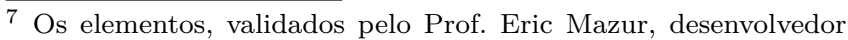
do método, são: (i) o professor adapta suas ações às respostas dos alunos às tarefas desenvolvidas em classe; (ii) os alunos não são avaliados nas tarefas de aula; (iii) os estudantes têm um tempo para pensar individualmente e se comprometer com uma resposta à tarefa antes de discutir com os colegas; (iv) são utilizadas questões conceituais na sala de aula; (v) as questões conceituais se baseiam em ideias prévias comuns e dificuldades dos alunos; (vi) as questões de sala de aula são de múltipla escolha; (vii) as tarefas são intercaladas ao longo da aula; (viii) os alunos discutem suas ideias a respeito das respostas às atividades com os seus colegas; (ix) os estudantes votam individualmente após a discussão entre os colegas.
}

que compõem o método, os autores organizaram os docentes, considerando a quantidade de elementos utilizados do IpC, em três categorias: Não Usuários (NU) não usam os elementos $(\mathrm{N}=10)$; Usuários Híbridos (UH) - usam entre 1 e 6 elementos $(\mathrm{N}=18)$; e Usuários Plenos (UP) - usam entre 7 e 9 elementos $(\mathrm{N}=7)$. Como resultado, os autores constataram que os docentes não estão conscientes dos princípios básicos e modificam elementos essenciais do método. Por exemplo, dentre os usuários híbridos: apenas $20 \%$ reportaram o comprometimento individual com uma resposta à questão proposta em aula; $40 \%$ argumentaram que raramente ou nunca pedem aos estudantes para discutirem entre si; e apenas $10 \%$ pediram para que os estudantes votassem após a discussão.

Em outra pesquisa, os mesmos pesquisadores do estudo anterior avaliaram as barreiras e vantagens percebidas por esses 35 professores de Física universitária, familiarizados com o IpC. A partir de entrevistas com relação à implementação do método e da organização dos docentes, definida no artigo de Dancy, Henderson e Turpen [8], Turpen, Dancy e Henderson [23. evidenciaram que os docentes percebem vantagens em alinhar suas práticas ao IpC, especialmente, porque o IpC não é centrado em aulas expositivas (mencionado por 6/7 UP e 14/18 UH) e por vivenciar experiências positivas com o método (5/7 UP, 10/18 UH e 5/10 NU) no passado. Em contrapartida, as razões mais comuns para que os docentes não utilizem o IpC são: o tempo para mudança da prática docente (10/18 UH e 9/10 $\mathrm{NU})$, a dificuldade de cobrir todo o conteúdo requerido institucionalmente $(9 / 18 \mathrm{UH}$ e $5 / 10 \mathrm{NU})$ e a dificuldade para engajar os alunos nas atividades ( $7 / 7$ UP). Dessa maneira, é possível notar que as barreiras percebidas por UP e UH são diferentes das percebidas pelos não usuários do método. Em geral, aqueles que utilizam o método percebem barreiras em relação à implementação, como a seleção de boas questões conceituais que gerem discussões entre os alunos; já aqueles que não utilizam o IpC relatam dificuldades relacionadas à falta de tempo.

Outros estudos que analisam a implementação de inovações didáticas de modo geral apontam uma defasagem entre o recomendado pelos pesquisadores e a prática dos professores, sobretudo em nível universitário. Por exemplo, Henderson e Dancy [24] indicam a interpretação errônea dos métodos e a baixa confiança em pesquisas em Ensino de Física como possíveis barreiras à adoção de uma inovação didática. Já Henderson [24] utilizou a TDI como ponto de partida para compreender o processo de mudança e identificar as barreiras enfrentadas por um professor ao adotar métodos interativos de ensino. Como resultado desse estudo o autor aponta a falta de compreensão dos princípios do método por parte do docente como fator limitante para a adoção de inovações. Além disso, ele indica as crenças de ensino aprendizagem e o planejamento otimista das atividades 
como barreiras do professor para inovar em sala de aula. Em estudo similar, Henderson e Dancy [10] indicam que existem diferentes expectativas sobre o uso dos métodos de ensino entre docentes e pesquisadores.

Ainda, Henderson e Dancy [25, ao realizarem um estudo com cinco docentes de Física, detectaram alguns fatores situacionais que limitavam a adoção de um método interativo de ensino, apesar de crenças docentes compatíveis. São eles: atitude negativa dos estudantes em relação à universidade; expectativa do professor de cobrir todo o conteúdo; falta de tempo; normas do departamento; resistência dos estudantes quanto à interação com outros colegas; quantidade de estudantes e a disposição tradicional das salas.

Dancy e Henderson [26] também identificaram a resposta pouco favorável dos estudantes aos métodos interativos, a preocupação de cumprir o programa da disciplina e a necessidade de tempo para a preparação dos materiais para as aulas como dificuldades enfrentadas pelos professores ao tentar inovar. E ainda identificaram como barreira o sentimento do professor de que suas modificações não estavam ocorrendo da maneira esperada. Pundak e Rozner [27] ao realizar um estudo, amparados pela TDI, em que investigaram o processo de implementação de métodos ativos por professores de Física e Cálculo, identificaram dificuldades relacionadas ao uso de tecnologias e ao tempo para implementação dos métodos e preparação dos materiais das aulas. Em contexto brasileiro, um estudo empírico em duas universidades públicas, realizado por Müller [9], identificou que o IpC também sofreu modificações ao longo do tempo. Segundo o autor, tais modificações foram realizadas devido às crenças dos docentes, à dificuldade de cumprir o cronograma de conteúdos da disciplina, aos contextos de ensino e às suas experiências anteriores e necessidades específicas.

Como elemento auxiliar para uma implementação bem-sucedida e continuação do uso de inovações didáticas, Müller [9], Henderson, Beach e Famiano [28] e Wieman, Deslaurius e Gilley 29] apresentam o suporte de um professor experiente. Müller [9] recomenda que haja diálogo e uma maior proximidade entre o pesquisador (agente inovador), que tem experiência com a inovação, e o adotante, que conhece as condições materiais que possibilitam, ou dificultam, a mudança em seu contexto. Tais resultados corroboram a hipótese de Henderson, Dancy e Niewiadomska-Bugaj [30] de que a falta de suporte para implementação e enfrentamento dos problemas que surgem naturalmente ao mudar a prática docente é a causa que leva a professores que conhecem uma ou mais estratégias inovadoras nunca a testarem ou descontinuarem após utilizá-la.

Todos esses estudos apresentados evidenciam a ocorrência e necessidade de modificações nos métodos de ensino, sobretudo no IpC, e indicam diversas barreiras relacionadas aos processos de adoção e reinvenção da inovação. No entanto, poucos foram os estudos identificados que analisaram as mudanças e dificuldades em contexto brasileiro de ensino.

\section{Teoria da Difusão de Inovação}

Em 1962, o sociólogo Everett Rogers propôs a Teoria da Difusão de Inovações, através do livro Diffusion of Innovations [18. Rogers, em sintonia com os demais estudiosos sobre difusão da época, reconhece que a decisão de um indivíduo inovar não é instantânea, mas sim um processo com diferentes ações. O autor inicia o primeiro capítulo do livro declarando que "Adotar uma nova ideia, mesmo quando apresenta vantagens óbvias, é difícil." [18] (p. 1).

Para Rogers uma inovação pode ser entendida como "uma ideia, prática ou objeto que é percebido como novo por um indivíduo, organização ou outra unidade de adoção." [18] (p. 12). Ou seja, a novidade de uma inovação é relativa à unidade de adoção que irá adotála ou não, sem necessidade de envolver apenas novos conhecimentos. Dessa forma, um indivíduo "pode ter conhecimento de uma inovação há algum tempo, mas ainda não desenvolveu uma atitude favorável ou desfavorável em relação a ela, nem a adotou ou a rejeitou." [18] (p. 12). Em outras palavras, a "novidade" de uma inovação pode acontecer tanto ao conhecer, ser persuadido a experimentá-la ou decidir adotá-la.

Parte das inovações em que se analisa a difusão são consideradas inovações tecnológicas. No entanto, o autor destaca a distinção dos conceitos de "inovação" e "tecnologia". Uma tecnologia "é um projeto de ação instrumental que reduz a incerteza nas relações de causaefeito envolvidas na obtenção do resultado desejado." [18] (p. 13). Ou seja, tecnologia é um tipo de informação sobre a inovação que reduz a incerteza sobre ela. Além disso, Rogers destaca dois componentes da tecnologia: i) o hardware, que consiste em ferramentas materiais da inovação tecnológica; e ii) o software, que é a base de informações e conhecimentos sobre essas ferramentas. No presente estudo, entendemos as inovações didáticas como inovações tecnológicas. Nesse sentido, as estratégias práticas dos métodos de ensino constituem o hardware, o qual incorpora elementos teóricos que o sustentam (software), que chamamos aqui de princípios pedagógicos.

Rogers [18] apresenta um modelo de decisão pela inovação que consiste em uma série de ações diferentes que ocorrem ao longo do tempo, uma vez que a decisão de inovação de um indivíduo ou organização não é um ato instantâneo. O modelo proposto possui cinco etapas: conhecimento, persuasão, decisão, implementação e confirmação. Cabe salientar que essas etapas não ocorrem, necessariamente, nessa ordem; e algumas delas podem ocorrer de forma simultânea.

Previamente aos primeiros conhecimentos sobre uma inovação, isto é, ao início do processo de decisão, a unidade de adoção deve satisfazer alguns dos 
seguintes pré-requisitos: perceber uma necessidade ou problema; possuir uma personalidade inovadora; apresentar práticas anteriores compatíveis com a inovação; $e$ contar com normas sociais que legitimem a incorporação da nova prática, ideia ou objeto. Para o autor, as normas sociais são padrões de comportamento estabelecidos para os membros de um sistema social [18] (p. 26). Dessa forma, essas normas acabam por definir uma variedade de comportamentos toleráveis e esperados para os membros do sistema social em questão. Nesse sentido, entendemos que os professores que investigamos ao implementarem seus PEs em sala de aula foram guiados por diversas normas sociais. Ou seja, seu comportamento e consequentemente suas ações em sala de aula foram, em parte, definidas previamente pelos membros do sistema social ao qual pertencem, pela instituição em que atuavam.

Atendidos os pré-requisitos pelo possível adotante, o processo de adoção de inovações começa com o conhecimento. Nessa etapa, a unidade de adoção é exposta a uma inovação e passa a obter alguns conhecimentos sobre o seu funcionamento e seus princípios. Apesar da busca por informações estar concentrada na fase do conhecimento, é possível que uma inovação seja utilizada sem que o adotante adquira, em qualquer das etapas, algum conhecimento acerca de seus princípios. Nesses casos, seu uso é suscetível a falhas e pode resultar na descontinuação.

A segunda fase, da persuasão, consiste na formação de uma atitude (des)favorável da unidade de adoção com relação à inovação, buscando ativamente informações sobre a nova ideia e as interpretando. E, para Rogers [18], essas atitudes são consideradas influenciadas por cinco características principais da inovação percebidas pelo adotante. São elas: vantagem relativa (grau em que uma inovação é percebida como melhor que a estratégia antecessora, a ser substituída); compatibilidade (grau que uma inovação é compatível com os valores existentes, experiências precedentes e necessidades percebidas); complexidade (grau que uma inovação é percebida como difícil de utilizar e/ou entender); testabilidade (grau que uma inovação pode ser experimentada, em uma base limitada); observabilidade/visibilidade (grau em que os resultados de uma inovação são visíveis para outros indivíduos).

A etapa da decisão é o momento em que a unidade de adoção se envolve em atividades, como conversas com os pares experientes ou observações de colegas durante a implementação (i.e., experiência vicária), que levam à escolha da adoção ou rejeição da inovação. A etapa da implementação inicia quando a unidade de decisão coloca em prática uma inovação. Essa fase envolve uma mudança de comportamento do adotante, bem como evidencia os problemas de como efetivamente colocar em prática a inovação. É esperado que a maior parte das reinvenções ocorram durante a implementação.

Para Rogers [18] reinvenção é "o grau em que uma inovação é alterada ou modificada por um usuário no processo de adoção e implementação." (p. 180). É esperado que uma inovação, ao ser adotada, seja alterada ou adaptada em certo grau para atender as especificidades do contexto em que será implementada. No entanto, modificações mais profundas, que desarticulam os princípios que sustentam as qualidades da inovação, podem chegar ao ponto de não modificar, ou até piorar, a prática antecessora. É importante frisar que adotar uma nova ideia, prática ou objeto não significa implementar um padrão rígido estabelecido pela inovação, mas sim implementá-la ativamente, personalizando-a para atender as especificidades de um contexto particular.

Nesse sentido, reinvenções naturalmente ocorrem e uma forma de identificá-las é aferir "o número de elementos em cada implementação de uma inovação que são similares, ou diferentes, da versão principal da inovação" 18 (p. 184). É justamente desta maneira que a nossa pesquisa avaliou quais reinvenções mais frequentes realizadas pelos docentes ao adotar o IpC. Ou seja, para determinar se houve reinvenção do método avaliamos o uso de cada característica percebida como essencial a ele. Por fim, vale salientar que a reinvenção não ocorre exclusivamente durante a implementação, porém esse é o momento em que é mais provável que ocorra.

A última etapa do processo de decisão de inovação consiste na confirmação (reforço da sua decisão pela adoção) ou descontinuação (rejeição da inovação) da inovação. Para Rogers [18, a descontinuação pode ser devido ao conhecimento de outra ideia melhor, ou pela insatisfação com os resultados da inovação. E, tal insatisfação pode ser pelo uso inadequado da inovação que pode levar o adotante a não perceber vantagem relativa em sua adoção.

\section{Metodologia}

Para responder à questão de pesquisa deste estudo inicialmente foi realizada uma análise de conteúdo [19] das dissertações e PEs de professores que implementaram o IpC em aulas com temas de Física durante o MPE, entre 2004 e 2020. Devido à ausência de informações sobre a implementação de várias características do método, em alguns documentos, foi necessário realizar uma coleta de dados adicionais. Para isso elaboramos um questionário com questões baseadas nas etapas de implementação e confirmação de Rogers [18] e nas categorias definidas para a análise, expostas na Seção 4.1 .

A seguir apresentamos o delineamento metodológico para a análise de conteúdo das dissertações e, na sequência, o delineamento para coleta e análise dos dados adicionais, a partir da criação e aplicação do questionário.

\subsection{Análise de conteúdo das dissertações}

Para realização do estudo das dissertações e PEs, adotamos as orientações metodológicas da análise de conteúdo 
de Laurence Bardin 19. A proposta metodológica da autora prevê três fases: (i) pré-análise; (ii) exploração do material; (iii) tratamento dos resultados, inferência e interpretação.

A primeira etapa, pré-análise, consiste na organização, na qual inicialmente ocorre a escolha dos documentos a serem analisados e se realiza uma leitura flutuante para tomar o primeiro contato e definir objetivos, caso não estejam previamente definidos. A segunda etapa, exploração do material, corresponde a análise propriamente dita, onde ocorre a execução dos objetivos definidos na pré-análise, ou antes do início do estudo. Nessa etapa são criadas as categorias ou adaptadas aquelas definidas a priori, e realizada a codificação, que possibilita uma representação dos resultados das mensagens analisadas. A terceira e última etapa, tratamento dos resultados, inferência e interpretação, pode ser entendida como a síntese e seleção dos resultados, colocando em relevo as informações encontradas com a análise; e a respectiva interpretação, propondo uma nova análise ou utilizando os resultados para fins teóricos ou pragmáticos.

A primeira e segunda etapa da análise de conteúdo realizadas no presente estudo são apresentadas a seguir e a terceira etapa corresponde à seção de resultados e discussões.

\section{(i) Pré-análise}

A seleção dos materiais se deu com base no nosso objetivo de analisar as reinvenções e justificativas relatadas em dissertações de MPE e PEs, em que os professores, autores, utilizaram o método IpC em aulas com temas de Física. Realizamos a busca pelas dissertações no Catálogo de Teses e Dissertações da CAPES e em planilhas de dados sobre o MNPEF disponíveis na plataforma Sucupira, publicadas no período de 2004 (ano de publicação das primeiras dissertações do MPE) a 2020 .

Restringimos o escopo da seleção das dissertações apenas para aquelas que relatavam a implementação do IpC durante o MPE em aulas de Física. Para identificar esses documentos utilizamos, no catálogo da CAPES, os seguintes termos de busca: "Instrução pelos Colegas" OR "Instrução pelos Pares" OR "Instrução por Pares" OR "Peer Instruction" 8 Nas planilhas a busca foi feita manualmente a partir da leitura de todos os títulos e resumos. Elegemos assim 45 dissertações de MPE com temas de Física que relatavam a implementação do método selecionado.

\section{(ii) Exploração do material}

Com o objetivo de responder à questão de pesquisa proposta, em que buscamos identificar as principais mo-

\footnotetext{
8 Descritores escolhidos com base nos conceitos identificados em artigos e livro de divulgação da metodologia ativa escolhida.
}

dificações no método e as razões para as mudanças, elaboramos 11 categorias que representam características fundamentais do Peer Instruction. Elas foram adaptadas das categorias propostas por Dancy e colaboradores [8, 23. A categorização foi realizada através do recorte das unidades de registro e de context ${ }^{9}$ no texto digital das dissertações e PEs importados para o software de análise dados qualitativos Nvivo ${ }^{\circledR} 12$. As categorias usadas em nossa análise foram:

(C1) Preparação prévia como indicado pelo método;

(C2) Análise das respostas dos alunos à preparação prévia;

(C3) Exposições orais breves;

(C4) Questões intercaladas com exposições orais;

(C5) Reflexão individual do estudante para cada teste conceitual;

(C6) Primeira votação dos testes conceituais individual;

(C7) Discussão entre os colegas;

(C8) Segunda votação dos testes conceituais individual;

(C9) Aplicação de testes conceituais em sala de aula;

(C10) Questões em sala de aula, testes conceituais, não são pontuadas por acerto e erro;

(C11) Tarefas de preparação prévia são avaliadas apenas por esforço ou participação.

Dentre os motivos para adaptação das categorias está o fato de que as características originais, propostas por Dancy, Henderson e Turpen [8] eram utilizadas para análise in loco, isto é, não foram propostas visando a análise de relatos escritos. Ademais, a partir da leitura flutuante e primeira tentativa de recorte e categorização, percebemos a necessidade de maior especificação dos elementos do método. Tais mudanças foram realizadas para estabelecer a pertinência e a homogeneidade das categorias. A produtividade, objetividade e fidelidade influenciaram na decisão de criar categorias objetivas para cada uma das ações propostas no método sustentadas por princípios pedagógicos.

Em nosso estudo, os referidos princípios correspondem à base de informações do método de ensino, relacionados à componente denominada software por Rogers, conforme apontado na seção 3 . Os princípios pedagógicos do método, e as categorias que se relacionam a cada um deles, são apresentados no Quadro 1 .

De acordo com as informações expostas no Quadro 1 é possível notar que, por exemplo, o sistema de votação adotado (e.g., clickers, flashcards, plickers) não se caracteriza como um elemento fundamental do método, pois não está associado aos princípios pedagógicos, caracterizando-se em um aspecto meramente técnico.

\footnotetext{
$\overline{9}$ Uma unidade de registro corresponde ao fragmento do conteúdo que possibilita a categorização e a contagem frequencial. E uma unidade de contexto representa o trecho, que compreende a unidade de registro, que possibilita compreender a significação exata da unidade de registro.
} 
Quadro 1: Princípios pedagógicos que sustentam cada característica (categoria) do Peer Instruction.*

Princípio pedagógico $\mathrm{C} 1 \quad \mathrm{C} 2 \quad \mathrm{C} 3$

Um estudante pode aprender com o outro.

O desenvolvimento do pensamento crítico e da habilidade de argumentação dos alunos pode auxiliar na compreensão conceitual dos conteúdos.

O engajamento cognitivo dos discentes com atividades de ensino auxilia na promoção da aprendizagem.

Melhores resultados de aprendizagem podem ser alcançados se os alunos forem corresponsáveis por ela.

O tempo em sala de aula deve ser valorizado com o engajamento ativo dos estudantes nas atividades.

A disponibilidade de tempo para que cada estudante reflita sobre os conceitos, no seu próprio ritmo, auxilia na aprendizagem.

Avaliações formativas auxiliam na aprendizagem.

O desenvolvimento de hábitos de estudo auxilia na aprendizagem.

A compreensão conceitual é fundamental na aprendizagem de Física e auxilia na resolução de problemas.

Os conhecimentos prévios dos alunos são essenciais para a aprendizagem.

\begin{tabular}{|c|c|c|c|c|c|c|c|c|c|c|}
\hline $\mathrm{C} 1$ & $\mathrm{C} 2$ & C3 & $\mathrm{C} 4$ & C5 & C6 & $\mathrm{C} 7$ & C8 & C9 & $\mathrm{C} 10$ & C11 \\
\hline & & & & & & $\mathrm{X}$ & & & & \\
\hline & & & & $\mathrm{x}$ & & $\mathrm{x}$ & & & & \\
\hline $\mathrm{X}$ & & & $\mathrm{x}$ & $\mathrm{x}$ & & $\mathrm{x}$ & & & & \\
\hline $\mathrm{X}$ & $\mathrm{x}$ & & & $\mathrm{x}$ & $\mathrm{x}$ & & $\mathrm{x}$ & & & $\mathrm{X}$ \\
\hline $\mathrm{X}$ & $\mathrm{x}$ & $\mathrm{x}$ & $\mathrm{x}$ & & & $\mathrm{x}$ & & & & $\mathrm{x}$ \\
\hline $\mathrm{X}$ & & & $\mathrm{x}$ & $\mathrm{x}$ & & & & & & \\
\hline & & & & & & & & & $\mathrm{x}$ & $\mathrm{X}$ \\
\hline $\mathrm{X}$ & & & & & & & & & & $\mathrm{x}$ \\
\hline $\mathrm{x}$ & & & & $x$ & & $\mathrm{x}$ & & $\mathrm{x}$ & & \\
\hline & $x$ & & $\mathrm{x}$ & & & $\mathrm{x}$ & & & & \\
\hline
\end{tabular}

*Este quadro foi elaborado a partir da investigação apresentada em F. Percheron, A.A. Petter, T. Espinosa e I.S. Araujo, Ensino de Ciências e Tecnologia em Revista, no prelo (2021).

Por outro lado, o que corresponde a uma categoria fundamentada é o registro individual dessas respostas.

Cada trabalho foi avaliado de acordo com possíveis alterações detectadas durante a análise de informações pertinentes a cada categoria, com a seguinte escala: "Modificado"; "Original"; "Sem informação"; e "Não se aplica". Os itens "Modificado" e "Original" se referem à comparação das ações implementadas nas dissertações e PEs em relação ao que é preconizado pelo autor do método IpC em seus trabalhos. Foram classificados como "Sem informação" os textos cujos autores não mencionaram, direta ou indiretamente, quaisquer indícios que possibilitassem a inferência de aplicação ou não da categoria em análise. Já a classificação "Não se aplica" foi empregada em situações em que uma modificação em uma categoria levou a ausência da característica em análise. Por exemplo, quando constatado que o autor não utilizou a tarefa de preparação prévia (C1) não faz sentido aferir se o mesmo avaliou a atividade prévia dos alunos para construção de suas exposições orais (C2), ou se atribuiu pontos pela realização da mesma (C11).

A partir dessas classificações foi possível identificar a frequência com que as características sofreram modificações. Tal procedimento viabilizou um melhor direcionamento na elaboração do questionário, uma vez que evidenciou quais categorias apresentaram um maior número de modificações, sem razões explícitas, e quais ações previstas no método $\mathrm{IpC}$ cujo relato textual das dissertações e PEs não trouxe informações suficientes para se avaliar como foram implementadas.

\subsection{Coleta de dados adicionais - questionário}

A coleta de dados adicionais se deu com a implementação de um questionário (vide Material Suplementar) elaborado com base nos resultados da análise de conteúdo e no referencial teórico. Buscamos complementar as informações já obtidas sobre a implementação do IpC pelos professores do MPE. Também incluímos perguntas sobre a continuidade do uso do método após o término do mestrado. Para verificar se as questões do questionário correspondiam às nossas expectativas com a pesquisa solicitamos que dois professores, doutores em ensino de Física, fizessem a validação do seu conteúdo. Para fins de refino do instrumento, realizamos uma aplicação piloto do questionário com dois professores participantes do estudo, que nos enviaram comentários sobre o entendimento das questões. Por fim, fizemos os devidos ajustes e convidamos todos os autores das dissertações selecionadas para o estudo, para respondê-lo. 
O questionário foi elaborado com base nas categorias estabelecidas para o estudo e disponibilizado aos professores no software LimeSurvey ${ }^{10}$ O instrumento contém 22 questões principais e outras 42 condicionadas às respostas das primeiras. Ou seja, o respondente é direcionado à próxima questão de acordo com as respostas que vai apresentando. Como exemplo temos as questões $6.1,6.3,6.4$, condicionadas a uma resposta afirmativa da questão 6, que visam identificar como ocorre a preparação prévia (Vide Material Suplementar).

Dentre as 64 questões, trinta e duas estão relacionados às modificações realizadas pelos professores durante o MPE (5-13 e questões condicionadas), organizadas segundo as categorias de análise, associadas com a etapa de implementação do método. Seis questões abordam as razões dessas mudanças durante o MPE $(6.1 .2 ; 6.5$; $7.3 ; 12.1 ; 13.7 ; 13.5 .2 ;)$. Outras nove questões se referem à implementação e confirmação do uso do método (15 e questões condicionadas), etapas do processo de decisão de inovação de Rogers em que as reinvenções são mais prováveis. Nessa dimensão havia questões sobre a descontinuidade ou continuidade do uso do método (confirmação da inovação), a frequência de uso e as adaptações necessárias para continuar implementando o método após a conclusão do MPE. Outras duas questões englobam as dificuldades enfrentadas para inovar em sala de aula apenas durante o MPE (14) e com relação a toda a experiência com o IpC (16), uma vez que entendemos as barreiras como possível justificativa para mudanças no método.

Para análise, organizamos as respostas do questionário de acordo com as categorias definidas para o estudo. Essa organização foi realizada em uma tabela a qual já havíamos gerado para organizar a classificação das dissertações. Para distinguir os dados advindos do questionário e das dissertações adicionamos uma nova coluna para cada categoria, dessa forma uma coluna representava as classificações originadas pela análise dos relatos nas dissertações e a outra apresentava as classificações derivadas das respostas ao questionário. Durante essa etapa foi necessário criar mais uma classificação para representar os casos em que o professor apresentou informações diferentes na dissertação e nas respostas ao questionário (denominada "Indeterminado").

\section{Resultados e Discussões}

Nesta seção apresentamos uma discussão sobre as reinvenções mais recorrentes realizadas no $\mathrm{IpC}$ e as justificativas para essas modificações, bem como levantamos algumas hipóteses para os resultados encontrados, discutindo esses com a literatura pertinente. Os dados apresentados correspondem à articulação dos resultados da análise das 45 dissertações e PEs com as respostas

\footnotetext{
$\overline{10}$ O Limesurvey é um software livre para aplicação de questionários online, disponível em https://www.limesurvey.org/pt/
}

fornecidas por 31 professores que se dispuseram a responder o questionário.

Dos 45 professores do nosso estudo, seis realizaram mudanças em mais de $50 \%$ das categorias analisadas e apenas dois não modificaram alguma característica do método (ID12; ID37 $7^{11}$. Tal resultado corrobora com uma das asserções do estudo de Henderson e Dancy [7] que indicam a raridade de professores no contexto norteamericano de ensino que usam as estratégias de ensino como recomendado pelo desenvolvedor.

Além disso, dos 14 participantes que não indicaram modificações na implementação do IpC (questão 5), apenas um (ID 12) realmente não o fez, de acordo com nossa análise das dissertações e respostas a outras questões do questionário. Os outros 13 docentes modificaram pelo menos uma característica. Cabe salientar que dois desses participantes, que não admitiram realizar modificações (ID10 e ID23), implementaram cinco mudanças, o que representa $45,5 \%$ de reinvenção no método. Ou seja, os professores, ao mudar algumas características do método não as relatam devido a um fator de esquecimento, relacionado com o tempo entre a implementação e a aplicação do questionário, ou, ainda, por não perceberem que uma mudança foi realizada.

Na Figura 1 apresentamos o panorama da frequência com que identificamos, para cada categoria as classificações definidas. Essas classificações levam em consideração a leitura das dissertações e PEs, bem como as informações coletadas no questionário.

Em sua maioria as classificações "Sem informação" estão relacionadas aos casos em que obtivemos acesso apenas à dissertação e ao PE. Frente a esse resultado sugerimos o uso de relatos mais detalhados, uma vez que esses podem possibilitar que futuros adotantes, a partir da leitura dos PEs ou dissertação, percebam e entendam as adaptações e dificuldades enfrentadas pelos autores durante a implementação do(s) método(s).

Conforme mencionado na Seção 3 , entendemos reinvenção como o grau que uma característica/inovação é modificada [18. Portanto, inicialmente verificamos quantitativamente as alterações em cada categoria e, na sequência, as analisamos qualitativamente, buscando identificar o grau com que a adaptação afetou os princípios pedagógicos que sustentam o método. Em relação ao tipo de instituição de ensino (público ou privado), não encontramos diferenças significativas nas reinvenções realizadas.

Das 11 categorias que representam as características essenciais do IpC, três apresentaram uma quantidade significativa de modificações (C4, C1, C9), pois mais de $50 \%$ dos professores as modificaram. Elas estão relacionadas com a preparação prévia, a dinâmica em sala de aula e a aplicação de questões conceituais em sala. Outras duas categorias ( 3 e C7), associadas ao tempo de exposição oral e ao encaminhamento da discussão entre

\footnotetext{
11 Para garantir o anonimato, cada um dos 45 professores foi identificado com um código, de ID01 até ID45.
} 


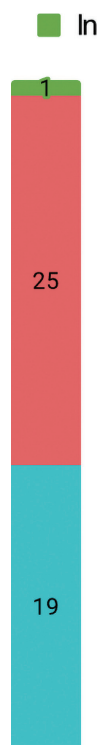

C1

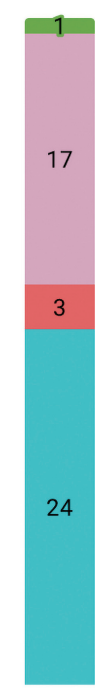

C2

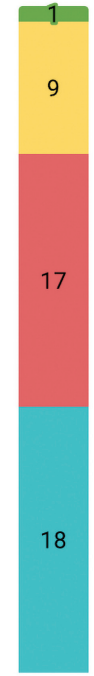

C3
Não se aplica

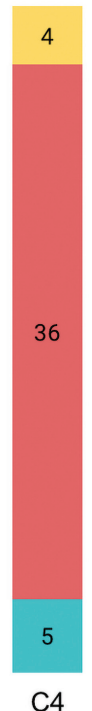

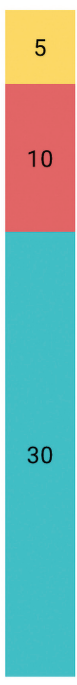

C5
Sem informação

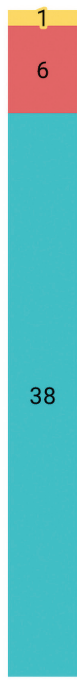

C6

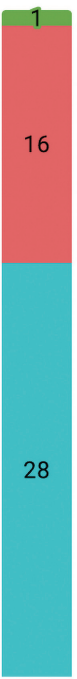

C7

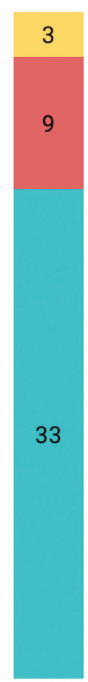

C8
Modificado
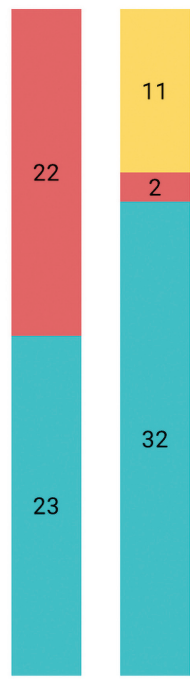

C10
Original

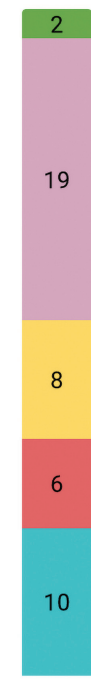

C11

Figura 1: Distribuição do total de trabalhos, em cada categoria de análise, em função de alterações introduzidas no método IpC. Fonte: elaborado pelos autores.

os alunos, foram alteradas por 17 e 16 docentes, respectivamente. Vale destacar que outras duas categorias relacionadas com a adaptação das aulas a partir das respostas dos alunos na preparação prévia $(\mathrm{C} 2)$ e a atribuição de notas para essas tarefas (C11) demonstraram uma quantidade moderada de classificações "Não se aplica", ou seja, não foram implementadas devido à decisão do professor de modificar C1. Nas demais categorias, associadas ao momento de votação $(\mathrm{C} 6, \mathrm{C} 8)$ e reflexão dos testes conceituais (C5) e à pontuação dos TC (C10), a quantidade de modificações não foi muito expressiva (até 10 participantes modificaram).

A seguir descrevemos as alterações realizadas nas cinco categorias $(\mathrm{C} 4, \mathrm{C} 1, \mathrm{C} 9, \mathrm{C} 3 \mathrm{e} \mathrm{C} 7)$ em que as reinvenções foram mais recorrentes e, quando identificado, apresentamos suas respectivas justificativas. Em alguns casos apresentados, um mesmo docente realizou mais de uma modificação, ou seja, o total de reinvenções ultrapassa 45, que representa o número total de professores que compõem a pesquisa. Ademais, um mesmo docente pode ter apontado mais de uma justificativa para a mesma reinvenção.

\subsection{Mudanças em questões intercaladas com exposições orais (C4)}

Em relação à $\mathrm{C} 4$ as mudanças identificadas nos trabalhos e nas respostas ao questionário, bem como as respectivas justificativas apresentadas pelos professores estão elencadas no Quadro 2

A mudança mais comum, feita por 28 professores, foi RC4a. Ou seja, primeiro os docentes realizavam a exposição oral de todo o conteúdo da aula e depois aplicavam os TCs. Em alguns desses casos, o professor também utilizava uma aula exclusiva para aplicação dos
Quadro 2: Reinvenções e justificativas apresentadas pelos docentes em relação à $\mathrm{C} 4$.

\begin{tabular}{|c|c|}
\hline Reinvenções & $\begin{array}{c}\text { Justificativas explicitadas } \\
\text { pelos docentes }\end{array}$ \\
\hline $\begin{array}{l}\text { RC4a } 12-\text { Aplicação dos } \\
\text { TCs ao final do } \\
\text { período/aula }(\mathrm{n}=28) \text {. }\end{array}$ & $\begin{array}{l}\text { Elevada quantidade } \\
\text { de dúvida dos alunos } \\
(\mathrm{n}=1) \text {. } \\
\text { Necessidade de } \\
\text { cumprir o conteúdo } \\
(\mathrm{n}=1) .\end{array}$ \\
\hline $\begin{array}{l}\mathrm{RC} 4 \mathrm{~b}-\text { Aula dedicada } \\
\text { exclusivamente à } \\
\text { aplicação dos TCs } \\
(\mathrm{n}=16) .\end{array}$ & $\begin{array}{l}\text { Elevada quantidade } \\
\text { de dúvida dos alunos } \\
(\mathrm{n}=1)\end{array}$ \\
\hline $\begin{array}{l}\text { RC4c - Aplicação dos } \\
\text { TCs em um único } \\
\text { momento na aula }(\mathrm{n}=7) \text {. }\end{array}$ & - \\
\hline $\begin{array}{l}\text { RC4d - Aplicação dos } \\
\text { TCs no formato de "lista } \\
\text { de exercícios" } \\
\text { disponibilizada aos alunos } \\
\text { no início da aula }(\mathrm{n}=1) .\end{array}$ & - \\
\hline
\end{tabular}

TCs (RC4b). O seguinte trecho ilustra essa reinvenção:

Primeiramente em uma aula de 55 minutos, foi feita uma exibição de um vídeo [.. .] Após o vídeo, que teve uma duração de aproximadamente 15 minutos, foram feitas algumas

\footnotetext{
12 Código para Reinvenção na Categoria 4 (RC4). As letras a, b, c e d representam as diferentes mudanças realizadas na categoria.
} 
perguntas pós-vídeos sobre a $1^{a}$ e $3^{a}$ Leis de Newton. Essas perguntas foram discutidas, ainda na primeira aula de forma dialogada entre os alunos e o professor, essa etapa teve uma duração aproximada de 15 minutos. Depois o professor explicou e enunciou a $1^{a}$ e $3^{a}$ Leis de Newton, a duração dessa etapa foi de aproximadamente 15 minutos. $\mathrm{Na}$ aula seguinte, foram apresentadas as questões conceituais com a metodologia IpC [Instrução pelos Colegas] e o uso do sistema de votação aqui desenvolvido. [...] Foram realizadas um total de 07 questões em 02 aulas de 55 minutos (ID44).

Para as modificações RC4a e RC4b apenas três professores apresentaram justificativas. Um deles aplicou todos os TCs ora no início, ora no final do período, nunca intercalando com outras atividades, em função da elevada quantidade de dúvidas dos alunos na preparação prévia. Segundo ele, uma exposição e discussão das respostas da tarefa de preparação prévia mais demorada implicou falta de tempo para aplicar todos os TCs da forma prevista pelo método. Também pela quantidade de dúvida dos alunos em relação ao conteúdo, outro docente destinou uma aula exclusiva para aplicar todos os TCs. O terceiro docente justificou a aplicação dos TCs ao final do período pela necessidade de cumprir todo o conteúdo. Com relação a essa última justificativa, entendemos que ela pode indicar a existência de normas sociais a respeito dessa ação que guiem algumas ações dos professores em sala de aula. Na TDI "as normas de um sistema social podem ser uma barreira à mudança" [18] (p. 26), ou seja, uma inovação para ser bem-sucedida deve apresentar suporte das normas sociais do contexto em que está sendo aplicada.

Frente a essas mudanças na C4, em que de certa forma os professores priorizaram a exposição do conteúdo em detrimento das discussões entre os colegas, evidenciamos como possível causa para todas adaptações a influência de crenças de ensino transmissionistas do docente, nas quais o professor é entendido como o transmissor dos conteúdos e os alunos os receptores. Nesse caso, o docente utilizou o tempo em sala de aula para garantir uma transmissão eficaz, e não o aproveitou para que, por exemplo, um aluno aprenda com o outro, em discussões sobre os conceitos. Outra hipótese está relacionada à influência da prática tradicional de propor questões ao final da aula expositiva, para exclusivamente avaliar a compreensão dos estudantes. Além disso, a pequena carga-horária semanal destinada à disciplina de Física e a quantidade excessiva de conteúdos a serem tratados podem ter levado os docentes a organizarem um conjunto de questões para ser aplicado ao final da aula, reduzindo o tempo que seria destinado à atividade de intercalar entre a aplicação de questões e pequenas exposições dos conceitos.

\subsection{Mudanças na preparação prévia (C1)}

Em relação à C1, o Quadro 3 apresenta as reinvenções identificadas e justificativas apontadas nos trabalhos e nas respostas ao questionário dos docentes, alunos do MPE.

Com relação às duas reinvenções mais recorrentes (RC1a e RC1b), um professor sugeriu as leituras esporadicamente, e outro solicitou, em aula, apenas o retorno das dúvidas e curiosidades sobre o material dos alunos. O seguinte trecho, apresenta o relato do autor desse segundo caso em sua dissertação.

[...] As aulas foram estruturadas tendo
no primeiro momento um breve comentário
e discussão sobre a TL, indagaçấo das
possíveis dúvidas após a leitura de cada tema
e ainda, se os alunos compreenderam a lin-
guagem abordada no texto e se abarcaram as
imagens em cada tema proposto (ID08).

Quadro 3: Reinvenções e justificativas apresentadas pelos docentes em relação à $\mathrm{C} 1$.

Justificativas explicitadas

Reinvenções pelos docentes

RC1a - Indicação de materiais para leitura prévia, sem questões sobre eles $(\mathrm{n}=11)$.

RC1b - Ausência de qualquer tarefa de preparação prévia $(\mathrm{n}=6)$.

RC1c - Tarefa de preparação realizada totalmente ou parcialmente em sala de aula $(\mathrm{n}=7)$.

RC1d - Indicação de leitura de materiais e resolução prévia de lista de exercícios numéricos $(\mathrm{n}=1)$. 
O autor deste recorte confirmou, em resposta ao questionário, que não aplicou questões sobre a leitura prévia. No entanto, não apresentou justificativa para isso.

Não foi possível identificar nas dissertações, a razão atribuída pelos professores para a eliminação das questões sobre a leitura (RC1a) ou da tarefa de preparação prévia por completo (RC1b). Já nas respostas ao questionário, três docentes apontaram suas razões para essas modificações, são elas: (i) falta de tempo do professor para analisar a resposta dos alunos antes da aula; (ii) falta de engajamento dos alunos nas atividades prévias e resistência discente para usar ambientes virtuais; e (iii) entendimento do professor de que a leitura seria suficiente para o aluno entender o conteúdo. Frente a essas justificativas levantamos a hipótese de que os três motivos apontados para RC1a e RC1b consistem em dificuldades devido às práticas anteriores dos docentes e discentes com relação ao processo de ensino-aprendizagem. Ou seja, tanto alunos como professores estão acostumados a realizar tarefas diferentes das propostas pelo método e tal mudança de suas práticas exige mais esforço para desempenhar novas tarefas, sem a percepção de vantagens relativas, observáveis, desde o início.

Dentre os seis professores que não utilizaram as tarefas de preparação prévia ( $\mathrm{RC} 1 \mathrm{~b})$, apenas um comentou no texto da dissertação e no questionário que não foi possível utilizá-las devido à resistência dos alunos ao uso de ambientes virtuais e à falta de engajamento dos alunos. É possível notar, na unidade de análise a seguir, que o método, em alguns casos, já foi apresentado sem considerar a preparação prévia:

\section{O método Instruções pelos Colegas (IpC)} consiste em, depois de uma rápida exposição do conteúdo, de cerca de 15 minutos, aplicarse alguns testes conceituais de múltipla escolha para os alunos responderem individualmente (ID20).

Nesses seis casos, RC1b, cinco não apresentaram a tarefa como parte integrante do IpC; e o docente que não utilizou por resistência e falta de engajamento estudantil indicou a preparação prévia como opcional. No questionário apenas um docente justificou a ausência dessa característica com a falta de engajamento dos alunos.

A não apresentação de questões em conjunto com os materiais indicados para leitura ( $\mathrm{RC} 1 \mathrm{a})$ deixa de oferecer ao aluno uma oportunidade dele próprio avaliar o quanto está conseguindo compreender e aplicar os conceitos. Além disso, retira a possibilidade de o professor preparar a aula de acordo com as dificuldades dos estudantes, passíveis de serem detectadas nas tentativas de respostas às questões prévias.

A completa ausência da tarefa de preparação prévia (RC1b), além dos prejuízos relacionados ao planejamento das aulas em termos das dificuldades e interes- ses da turma, restringe a possibilidade de um melhor aproveitamento do tempo em sala de aula para atividades de engajamento discente. Nesse caso, o tempo é usualmente destinado à apresentação do conteúdo por parte do professor. Essa modificação também reduz a responsabilidade do aluno sobre a própria aprendizagem.

Além dessas mudanças, identificamos sete professores que transpuseram, total ou parcialmente, a tarefa de preparação para a sala de aula (RC1c). Um desses docentes realizou a mudança devido à falta de tempo e engajamento dos alunos para fazer atividades fora de sala de aula e o outro pela falta de acesso à internet $\mathrm{e}$ computadores. Outros dois desses professores optaram por realizar apenas a leitura de um material em sala de aula devido à falta de engajamento dos alunos para realizar as atividades, como podemos perceber nas respostas apresentadas por eles no questionário:

\section{Porque as atividades de casa costumam ser de baixo aproveitamento. A maioria deles não leem materiais que solicitamos previ- amente, exceto quando condicionamos uma pontuação a eles (ID17). \\ A atividade prévia teve que ser feita em sala. Quando ficou para casa, pouquíssimos [alunos] fizeram (ID13).}

Tal adaptação, RC1c, desvia das intenções originais do método, uma vez que não sustenta a ideia de destinar o tempo de sala de aula para a discussão dos alunos. Contudo, nossa hipótese é que essa mudança representa uma solução encontrada pelo docente para viabilizar o uso da inovação no seu contexto.

Por fim, destacamos que nos trabalhos em que os professores apresentaram suas justificativas para as alterações, a falta de engajamento dos alunos é uma das principais razões às modificações (quatro dos 10 professores convergiram para essa justificativa), na etapa de preparação prévia $(\mathrm{C} 1)$. Tal resultado vai ao encontro das razões para não adotar um método ativo de ensino identificadas em estudos realizados em universidades norte-americanas por Henderson e Dancy [25], Turpen, Dancy e Henderson [23] e Dancy e Henderson [26]. Nessas pesquisas, as principais razões apontadas foram as atitudes negativas dos estudantes com relação ao método e com relação à universidade e a dificuldade do docente para engajar os estudantes.

\subsection{Mudanças na aplicação de testes conceituais em sala de aula (C9)}

Outra categoria com elevada quantidade de modificações foi a C9. Todas as 22 mudanças detectadas consistiram no uso de pelo menos uma questão numérica/formulista como teste conceitual. O recorte a seguir exemplifica as questões que eram utilizadas:

TC9 - (UFMG - adaptada) Um menino, balançando em uma corda dependurada em 
uma árvore, faz 20 oscilações em um minuto. Pode-se afirmar que seu movimento tem: (a) um período de 3 segundos. (b) um período de 60 segundos. (c) um período de 20 segundos. (d) uma amplitude de 5 centímetros (ID35).

De certo modo essa alteração não leva em conta que o método considera que a compreensão conceitual é fundamental na aprendizagem de Física e auxilia na resolução de problemas. Ou seja, o método prioriza a aprendizagem conceitual, uma vez que pode facilitar a resolução de problemas. No entanto, apesar de não ser desejável a escolha de questões apenas numéricas, a combinação de algumas dessas com testes conceituais não descaracteriza o método e podem, inclusive, viabilizar a sua implementação em algumas instituições. Como hipótese, poderíamos considerar que, entre as razões para as alterações realizadas nesta categoria, estão as expectativas de pais, alunos e da instituição de ensino sobre a responsabilidade do professor em ensinar à turma a resolver problemas que permitam os discentes serem aprovados em avaliações externas (e.g., ENEM, vestibulares). Tais avaliações costumam ser baseadas em questões que envolvem a aplicação de fórmulas e de cálculos para a área da Física.

\subsection{Mudanças nas exposições orais breves (C3)}

A quarta categoria que sofreu mais reinvenção foi C3. Identificamos nos trabalhos de 17 docentes um longo tempo destinado às exposições orais em pelo menos uma aula. Cinco desses professores admitem exceder o tempo de explanação em seus relatos, porém não informam o quanto. Dentre esses, um docente apontou que optou por realizar uma aula exclusiva para exposição do conteúdo e outra para aplicar os TCs por acreditar que o trabalho fluiria melhor dessa forma. Essa modificação e justificativa estão retratadas no seguinte trecho:

Neste método, as aulas são divididas em pequenas séries de apresentações orais do professor, onde ele enfatiza os conceitos mais relevantes a serem trabalhados. Em sequência, são apresentadas as questões conceituais de múltipla escolha, que denominamos de pós-teste, para os educandos responderem primeiramente individualmente e depois discutirem com os colegas (Oliveira, 2012). Em nosso trabalho, optamos por utilizar duas aulas para realizar essa atividade (pois acreditamos que o trabalho fluiria melhor dessa forma), uma aula para ministrar os conteúdos pertinentes e outra aula para apresentar as questões conceituais (ID39).

Dentre esses docentes, um argumentou que sua pouca experiência em sala de aula o levou a decidir realizar uma aula exclusiva para exposição do conteúdo e outra para aplicar os TCs. Outros dois explicitaram que investiram mais tempo nas exposições devido à quantidade de dúvidas apresentadas pelos alunos na TL. Um deles admite que, além da quantidade de dúvidas, dificuldades pessoais o levaram a optar por exposições mais longas. Outros dois justificaram essa mudança pelo fato de os alunos não realizarem a TL, ficando a cargo dos docentes a apresentação detalhada dos conteúdos.

Com relação a essa modificação entendemos que ela desvia em certo grau do princípio pedagógico que sustenta esse aspecto do método. Isso porque, o esperado é que o tempo de sala de aula seja destinado ao engajamento ativo do aluno e não somente à exposições do professor. No entanto, salientamos aqui que essas mudanças podem ser soluções dos docentes para dificuldades relacionadas com as tarefas de preparação prévia (C1).

A título de hipótese, as práticas preestabelecidas de um docente, que usualmente expõe em sala de aula todo o conteúdo, podem ter interferido no tempo dedicado pelo docente para a exposição dos conceitos. Assim como, a baixa carga horária e a grande quantidade de conceitos a serem cumpridos podem ter levado os docentes a dedicar maior parte do seu tempo para exposição oral desses conteúdos e deixar a resolução de problemas como tarefa secundária. Outra hipótese plausível é que as crenças de ensino e aprendizagem do professor, alinhadas a uma perspectiva transmissionista de ensino, podem ter induzido ele a utilizar mais tempo para exposição.

\subsection{Mudanças na discussão entre colegas (C7)}

No que diz respeito à $\mathrm{C} 7$, o Quadro 4 elenca as reinvenções e razões explicitadas pelos professores nos trabalhos e nas respostas ao questionário. Apesar de detectarmos um número alto de alterações $(n=17)$, apenas um professor não orientou os alunos a discutirem suas respostas para os TCs com os colegas, diferentemente dos resultados de Dancy, Henderson e Turpen [8], em que $7(40 \%)$ de 18 professores raramente ou nunca pediam para os alunos discutirem.

Com relação à $\mathrm{RC} 7 \mathrm{a}$, apenas um docente apresentou a carga horária limitada como justificativa. Pelo mesmo motivo, outro docente realizou a RC7c. Por fim, um professor alegou o desconhecimento de instrumentos de coleta e análise automática das respostas dos alunos aos TCs como razão para RC7b.

Frente às reinvenções RC7a, RC7b e RC7e, apresentadas no Quadro 4 entendemos que os professores que as implementaram realizaram a discussão entre os estudantes apenas mudando o momento ou as condições em que era indicada. Ou seja, essas alterações preservam as intenções originais do método. A saber: (i) um estudante pode aprender com outro; (ii) o desenvolvimento do pensamento crítico e da habilidade de argumentação dos alunos pode auxiliar na compreensão conceitual dos conteúdos; (iii) o tempo de sala de aula deve ser valorizado com o engajamento ativo dos aluno estudantes nas 
Quadro 4: Reinvenções e razões indicadas pelos docentes em relação à $\mathrm{C} 7$.

\begin{tabular}{|c|c|}
\hline Reinvenção & $\begin{array}{l}\text { Razões explicitadas } \\
\text { pelos docentes }\end{array}$ \\
\hline $\begin{array}{l}\mathrm{RC} 7 \mathrm{a} \text { - Interferência do } \\
\text { professor durante as } \\
\text { discussões, direcionando a } \\
\text { escolha das respostas } \\
(\mathrm{n}=7) .\end{array}$ & $\begin{array}{l}\text { Baixa carga horária da } \\
\text { disciplina }(\mathrm{n}=1) .\end{array}$ \\
\hline $\begin{array}{l}\text { RC7b - Encaminhar a } \\
\text { discussão entre os alunos } \\
\text { sobre os TCs } \\
\text { independentemente da } \\
\text { quantidade de acertos } \\
(\mathrm{n}=5) .\end{array}$ & $\begin{array}{l}\text { Falta de conhecimento } \\
\text { sobre instrumentos de } \\
\text { coleta e análise } \\
\text { automática das } \\
\text { respostas }(\mathrm{n}=1)\end{array}$ \\
\hline $\begin{array}{l}\text { RC7c - Substituição da } \\
\text { discussão em pequenos } \\
\text { grupos pela exposição de } \\
\text { um aluno para a turma } \\
\text { sobre sua resposta }(n=2) .\end{array}$ & $\begin{array}{l}\text { Baixa carga horária da } \\
\text { disciplina }(\mathrm{n}=1) \text {. }\end{array}$ \\
\hline $\begin{array}{l}\text { RC7d - Troca da discussão } \\
\text { por exposição oral do } \\
\text { professor }(n=1)\end{array}$ & - \\
\hline $\begin{array}{l}\mathrm{RC} 7 \mathrm{e} \text { - Indicação de } \\
\text { discussões após a votação } \\
\text { de vários TCs }(\mathrm{n}=1) .\end{array}$ & - \\
\hline $\begin{array}{l}\mathrm{RC} 7 \mathrm{f} \text { - Discussão } \\
\text { organizada por uma } \\
\text { estudante, que assumiu o } \\
\text { papel de líder de turma } \\
(\mathrm{n}=1) .\end{array}$ & - \\
\hline
\end{tabular}

atividades; (iv) a compreensão conceitual é fundamental na aprendizagem de Física e auxilia na resolução de problemas; (v) os conhecimentos prévios dos alunos são essenciais para a aprendizagem; (vi) o engajamento cognitivo dos discentes com atividades de ensino auxilia na promoção da aprendizagem. Para $\mathrm{RC} 7 \mathrm{c}, \mathrm{RC} 7 \mathrm{~d}$ e RC7f, entendemos que os pressupostos do método (i), (ii), (iii) e (vi) foram desconsiderados pelos seus autores. Destacamos aqui que devido ao pressuposto (i) estar relacionado apenas com essa característica do método (C7), sua modificação, se mal conduzida, pode debilitar o PI, impactando negativamente nos resultados advindos de sua implementação.

Por fim, uma hipótese explicativa para as mudanças em C7 é que a usual distribuição dos períodos de Física em mais de um dia da semana, a baixa carga horária da disciplina e a necessidade de cumprir uma elevada quantidade de conteúdos (normas sociais) podem ter levado alguns docentes a destinarem pouco tempo para as discussões, ou interferindo nelas para poderem avançar com o conteúdo.

\section{Considerações Finais}

Neste estudo foram evidenciadas as características do IpC que mais sofreram modificações quando implementadas em contexto brasileiro de ensino por professores, ex-alunos do MPE, durante a preparação de suas dissertações. As reinvenções mais frequentes detectadas foram: a ausência de uma tarefa de preparação prévia ou o uso apenas de leituras e/ou vídeos prévios; a aplicação dos testes conceituais apenas ao final do período; o uso de questões algébricas como testes conceituais; o tempo mais longo de exposição oral do professor; e a intervenção do docente na discussão ou sua realização independentemente do percentual de acertos na votação das questões conceituais.

Considerando todas as modificações identificadas, apresentamos algumas hipóteses gerais, orientadas por nossa leitura das dissertações e respostas aos questionários, observando as razões levantadas pelos professores sempre que presentes. De modo geral, o resultado vai ao encontro do que é apontado na literatura da área, com destaque para as seguintes justificativas: preocupação do professor em cumprir o conteúdo programado [23, 25, 26]; crenças de ensino e aprendizagem do docente desalinhadas com as que sustentam as práticas do método de ensino [24]; falta de tempo em sala de aula para realizar as atividades planejadas 24]; falta de compreensão dos princípios do método [8, 24]; e dificuldades para utilizar tecnologias em sala de aula [27.

Além dessas, apontamos que o possível desconhecimento de alguns princípios pode estar relacionado com o canal de comunicação, na acepção de Rogers [18, pelo qual o indivíduo tomou conhecimento do método.

Em relação à falta de informações nas dissertações sobre as mudanças realizadas no método, apontamos as seguintes hipóteses: alguns docentes não percebem que estão realizando reinvenções, por não terem compreendido corretamente as técnicas, ou as razões que as sustentam; e/ou se restringiram a apresentar o método, já adaptado ao próprio contexto de ensino, sem explicitar as modificações introduzidas, e assim evidenciar a intencionalidade de tais ações.

Independentemente das justificativas apontadas para as mudanças, uma hipótese para a ausência de informações explícitas sobre essas modificações pode estar relacionada com uma crença dos adotantes de que o método não é passível de modificação. No entanto, adaptações conscientes, que considerem os princípios pedagógicos que sustentam o método, são esperadas e desejáveis quando um método é levado de um contexto para outro, diferente do seu de origem.

Por fim, entendemos que a falta de informações na literatura acerca da estrutura básica do método, com apontamentos sobre elementos essenciais e características que podem ser adaptadas a diferentes contextos, pode dificultar sua disseminação. Nesse sentido, outra contribuição desse estudo está associada à 
identificação das características fundamentais do IpC bem como dos princípios pedagógicos atrelados a elas. Essa identificação pode servir como base para que futuros adotantes do método, professores atuantes do MPE, possam perceber, de forma consciente, as suas próprias modificações e apontá-las para futuros leitores. Esperamos que os resultados apresentados neste artigo, em especial, as hipóteses trazidas ao longo do trabalho, possam auxiliar futuras investigações no tema e assim contribuir para a melhoria no ensino de Ciências.

\section{Agradecimentos}

O presente trabalho foi realizado com apoio da Coordenação de Aperfeiçoamento de Pessoal de Nível Superior - Brasil (CAPES) - Código de Financiamento 001. Ives Solano Araujo agradece ao $\mathrm{CNPq}$ pela bolsa de Produtividade em Pesquisa.

\section{Material suplementar}

O seguinte material suplementar está disponível online: Questionário aplicado aos professores do estudo.

\section{REFERÊNCIAS}

[1] BRASIL, Lei de Diretrizes e Bases Da Educação Nacional - LDB. Lei $\mathrm{N}^{\circ}$ 9.394, de 20 de dezembro de 1996, Brasília, 1996. Disponível em: http://www.planalto.gov .br/ccivil_03/leis/19394.htm

[2] R.S. Araujo e D.M. Vianna, Ciência Educ. 17, 807 (2011).

[3] T. Espinosa, I.S. Araujo e E.A. Veit, Rev. Bras. Pesqui. Em Educ. Em Ciências 19, 373 (2019).

[4] E. Mazur, Peer Instruction?: A User's Manual (Prentice Hall, Nova Jersey, 1997), v. 1.

[5] E. Mazur, Peer Instruction: A Revolução Da Aprendizagem Ativa (Penso, Porto Alegre, 2015), v. 1.

[6] M.G. Müller, I.S. Araujo, E.A. Veit e J. Schell, Rev. Bras. Ensino Física 39, e3403 (2017).

[7] C. Henderson e M.H. Dancy, Phys. Rev. Spec. Top. Phys. Educ. Res. 5, 020107 (2009).

[8] M. Dancy, C. Henderson e C. Turpen, Phys. Rev. Phys. Educ. Res. 12, 010110 (2016).

[9] M.G. Müller, Adoção e Difusão de Inovações Didáticas Em Disciplinas de Física Geral: Estudos de Caso Em Duas Universidades Públicas Brasileiras. Tese de Doutorado, Universidade Federal do Rio Grande do Sul, Porto Alegre (2017).

[10] C. Henderson e M.H. Dancy, Am. J. Phys. 76, 79 (2008).

[11] CAPES, Avaliação Trienal: 2013. Coordenação de Aperfeiçoamento de Pessoal de Nível Superior. Documento de Área de Ensino (2013). Disponível em: https://www.go v.br/capes/pt-br/centrais-de-conteudo/Educao_Fsica_d oc_area_e_comisso_att08deoutubro.pdf

[12] BRASIL, Conselho Do MNPEF. Regimento Geral Do Mestrado Nacional Profissional Em Ensino de Física (2015). Disponível em: http://www.sbfisica.org.br/ m npef/images/Regimento_MNPEF_16_12_2015_.pdf
[13] CAPES, Área de Ensino. Orientações Para Novos APCNS. Comunicado $N^{o}$ 001/2012 (2012). Disponível em: https://docplayer.com.br/9848474-Comunicado-no-001-2012-area-de-ensino-orientacoes-para-novos-apc ns-2012-brasilia-22-de-maio-de-2012.html

[14] E.L.Q. Antunes Junior, Formação Continuada de Professores Em Larga Escala: Um Estudo Sobre o Mestrado Nacional Profissional Em Ensino de Física. Dissertação de Mestrado, Universidade Federal do Rio Grande do Sul, Porto Alegre (2018).

[15] E.D.A. Schäfer, Impacto Do Mestrado Profissional Em Ensino de Física Da UFRGS Na Prática Docente: Um Estudo de Caso. Tese de Doutorado, Universidade Federal do Rio Grande do Sul, Porto Alegre (2013).

[16] M.R.M. Prado, A Formação Pós-Graduada Em Ensino de Ciências Naturais e Matemática de Docentes Do IFRN: Implicações $\mathrm{Na}$ Atuação Docente. Dissertação de Mestrado, Universidade Federal do Rio Grande do Norte, Porto Alegre (2011).

[17] P.V. Rebeque, F. Ostermann e S. Viseu, Rev. Bras. Ensino Ciência e Tecnol. 10, 1 (2017).

[18] E.M. Rogers, Diffusion of Innovations, $5^{\mathrm{a}}$ ed. (Free Press, New York, 2003).

[19] L. Bardin, Análise de Conteúdo, (Almedina Brasil, São Paulo, 2011).

[20] K. Smith, Innov. Educ. Teach. Int. 49, 173 (2012).

[21] I.S. Araujo e E. Mazur, Cad. Bras. Ensino Física 30, 362 (2013).

[22] E. Mazur e J. Watkins, Just-In-Time Teaching: Across the Disciplines, Across the Academy (Stylus Publishing, Sterling, 2010).

[23] C. Turpen, M. Dancy e C. Henderson, Phys. Rev. Phys. Educ. Res. 12, 010116 (2016).

[24] C. Henderson, Am. J. Phys.73, 778-786 (2005).

[25] C. Henderson e M.H. Dancy, Phys. Rev. Spec. Top. Phys. Educ. Res. 3, 020102 (2007).

[26] M.H. Dancy e C. Henderson, AIP Conference Proceedings 1413, 163 (2012)

[27] D. Pundak e S. Rozner, J. Sci. Educ. Technol. 17, 152 (2008).

[28] C. Henderson, A. Beach, e M. Famiano, Am. J. Phys. 77, 274 (2009).

[29] C. Wieman, L. Deslauriers e B. Gilley, Phys. Rev. Spec. Top. - Phys. Educ. Res. 9, 023102 (2013).

[30] C. Henderson, M. Dancy, e M. Niewiadomska-Bugaj, Phys. Rev. Spec. Top. - Phys. Educ. Res. 8, 020104 (2012). 